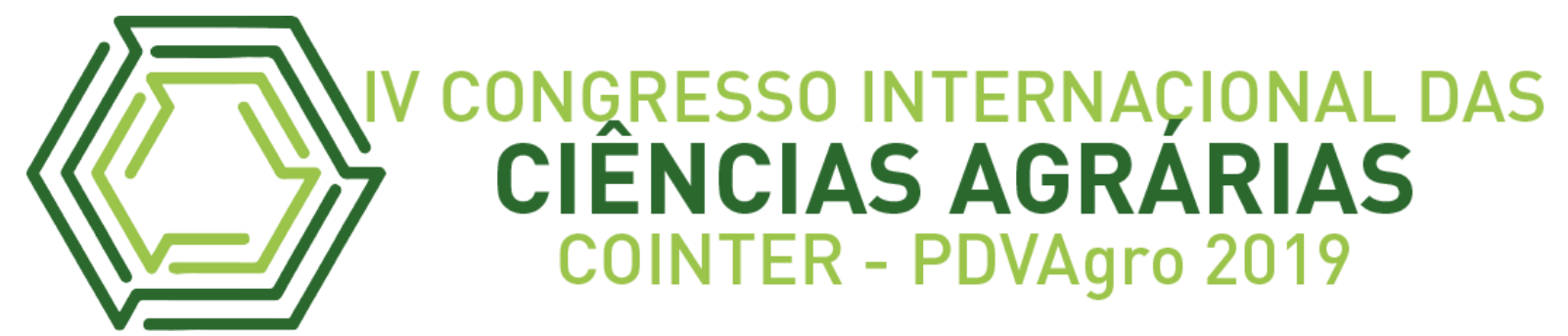

\title{
DINÂMICA DE PRODUÇÃO DO SITIO AGROECOLÓGICO TOLÚ, IGARAPÉ- AÇÚ, NORDESTE PARAENSE
}

\author{
DINÁMICAS DE PRODUCCIÓN DEL SITIO AGROECOLÓGICO TOLÚ, \\ IGARAPÉ-AÇÚ, NORESTE PARAENSE
}

\section{PRODUCTION DYNAMICS OF THE AGROECOLOGICAL SITE TOLÚ, IGARAPÉ- AÇÚ, NORTHEAST PARAENSE}

Apresentação: Comunicação Oral

Taiana do Carmo Farias ${ }^{1}$; Bernardo Milhomes Leão ${ }^{2}$; Ana Karlla Magalhães Nogueira ${ }^{3}$

DOI: $\underline{\text { https://doi.org/10.31692/2526-7701.IVCOINTERPDVAgro.2019.0071 }}$

\begin{abstract}
Resumo
O objetivo do trabalho foi analisar os aspectos econômicos referentes a concessão de insumos, os manejos e o escoamento dos produtos ofertados pelo Sítio Agroecológico Tolú situado no município de Igarapé-Açu, Nordeste Paraense. Também se pretendeu discutir os desafios e as perspectivas dos agricultores de produzir de forma sustentável, à luz de aspectos socioeconômicos e ambientais. Nesse contexto, a agroecologia incorpora o funcionamento ecológico necessário para uma agricultura sustentável, mas ao mesmo tempo aplica princípios de equidade na produção, de maneira que suas práticas permitam um acesso igualitário aos meios de vida. Portanto, o desenvolvimento sustentável tem como eixo central a melhoria da qualidade de vida humana dentro dos limites da capacidade de um determinado ecossistema e, na sua consecução, as pessoas, ao mesmo tempo que são beneficiários, são instrumentos do processo, sendo seu envolvimento fundamental para o alcance do sucesso desejado. O tipo da pesquisa caracteriza-se como estudo de caso e de natureza qualitativa quantitativa. Para a obtenção dos dados realizou-se entrevistas e aplicação de questionário semiestruturado junto aos proprietários do Sítio no mês de fevereiro de 2019. A partir da análise dos dados constatouse uma grande diversidade de produtos ofertados pelos agricultores e manejos utilizados para a condução da produtividade, como a utilização da compostagem laminar. Também foi observado que as vendas duplicaram após a adoção da entrega em domicílio de seus produtos, valendo-se dos meios digitais para encurtar a relação com seus clientes. Pode-se concluir que a unidade familiar agrícola adota variadas formas de agregação de valor aos seus produtos e que a forma
\end{abstract}

\footnotetext{
1 Graduanda em Agronomia pela Universidade Federal Rural da Amazônia (UFRA). E-mail: taiana.farias97@gmail.com

2 Graduando em Agronomia pela Universidade Federal Rural da Amazônia (UFRA). E-mail: bermilhomes@gmail.com

3 Doutora em Desenvolvimento Sustentável do Trópico Úmido (PPGDSTU)/NAEA/UFPA. Professora Adjunta da Universidade Federal Rural da Amazônia (UFRA). E-mail: karllamagalhaes@ufra.edu.br
} 
de produção sustentável proporcionou maior rentabilidade e benefícios sociais, econômicos e ambientais.

Palavras-Chave: agroecologia, economia, desenvolvimento sustentável, agricultura familiar

\title{
Resumen
}

El objetivo de este estudio fue analizar los aspectos económicos relacionados con la concesión de insumos, la gestión y la disposición de los productos ofrecidos por el sitio agroecológico de Tolú ubicado en el municipio de Igarapé-Açu, Nordeste Paraense. También se intentó discutir los desafíos y perspectivas de los agricultores para producir de manera sostenible, a la luz de los aspectos socioeconómicos y ambientales, por lo tanto, la agroecología incorpora el funcionamiento ecológico necesario para una agricultura sostenible, pero al mismo tiempo aplica los principios de equidad en la producción. Para que sus prácticas permitan un acceso equitativo a los medios de vida, por lo tanto, el desarrollo sostenible tiene como eje central el mejoramiento de la calidad de vida humana dentro de los límites de la capacidad de un ecosistema determinado y, en su logro, las personas, al mismo tiempo. En el momento en que son beneficiarios, son instrumentos del proceso, siendo su participación fundamental para alcanzar el éxito deseado. El tipo de investigación se caracteriza por el estudio de casos y la naturaleza cuantitativa cualitativa. Para obtener los datos, se aplicaron entrevistas y un cuestionario semiestructurado a los propietarios del Sitio en febrero de 2019. Sobre la base del análisis de los datos, una gran diversidad de productos ofrecidos por los agricultores y las administraciones utilizadas para la conducción de los La productividad, como el uso de compostado laminado. También se observó que las ventas se duplicaron después de la adopción de la entrega a domicilio de sus productos, utilizando medios digitales para acortar la relación con sus clientes. Se puede concluir que la unidad familiar agrícola adopta varias formas de valor agregado a sus productos y que la forma sostenible de producción ha proporcionado más rentabilidad y beneficios sociales, económicos y ambientales.

Palabras Clave: Agroecología, economía, desarrollo sostenible, agricultura familiar.

\begin{abstract}
The objective of this work was to analyze the economic aspects related to the concession of inputs, the management and the disposal of the products offered by the Tolú Agroecological Site located in the municipality of Igarapé-Açu, Nordeste Paraense. It was also intended to discuss the challenges and perspectives of farmers to produce sustainably in the light of socioeconomic and environmental aspects, thus, agroecology incorporates the ecological functioning necessary for sustainable agriculture, but at the same time applies principles of fairness in the production, so that their practices allow an equal access to the means of life, therefore, sustainable development has as its central axis the improvement of the quality of human life within the limits of the capacity of a certain ecosystem and, in its attainment, the people, at the same time they are beneficiaries, are instruments of the process, being their fundamental involvement to reach the desired success. The type of research is characterized as case study and qualitative quantitative nature. In order to obtain the data, interviews and a semistructured questionnaire were applied to the owners of the Site in February 2019. Based on the analysis of the data, a great diversity of products offered by the farmers and managements used for the conduction of the productivity, such as the use of laminate composting. It was also observed that sales doubled after the adoption of home delivery of their products, using digital
\end{abstract}


means to shorten the relationship with their customers. It can be concluded that the agricultural family unit adopts various forms of value added to its products and that the sustainable way of production has provided more profitability and social, economic and environmental benefits.

Keywords: agroecology, economics, sustainable development, family farming

\section{Introdução}

Considerando que a produção agrícola familiar é o sistema socioeconômico mais presente em áreas rurais do país, que pode se caracterizar majoritariamente por pequenas comunidades afastadas das regiões mais urbanizadas dos municípios, é perceptível que ainda se tem muitas problemáticas vigentes, como o abandono governamental e institucional, bem como o desenvolvimento lento referente a produção agrícola, tendo em vista que a agricultura familiar está mais representada em dispersão pelo território brasileiro quando comparada as grandes empresas do agronegócio* (WANDERLEY, 2000).

Frente a esta conjuntura, pode se admitir que os agricultores familiares têm sido atores diretos do empreendedorismo e inovação, principalmente no que se refere a produção sustentável, tendo em vista a desigualdade social que sofrem, o uso desenfreado de recursos naturais e de agroquímicos nos plantios da agricultura convencional e a aceitação cada vez maior de produtos que não tem grande impacto ambiental quando comparados a outros modelos de cultivo já bem difundidos pelo país como a monocultura (LAGO et al., 2006).

Veiga (1996) destaca algumas características do modelo familiar de agricultura, no que diz respeito a dinâmica produtiva e organizacional: ao contrário do modelo patronal que apresenta separação entre gestão e trabalho, neste modelo estas propriedades estão interacionados, o direcionamento do processo produtivo é decidido diretamente pelos proprietários, a diversificação de produção, se dá importância ao equilíbrio dos recursos naturais e na qualidade da vida, por fim, as escolhas são imediatas e adequadas ao alto grau de casualidade dos fatores de produção dentro da propriedade.

Veiga (1996) ressalta, ainda, a questão da sustentabilidade (equilíbrio, resiliência e isonomia), onde se tem na produção agrícola maiores vantagens de desenvolvimento por dar ênfase na diversificação e na flexibilidade de seu processo decisório.

\footnotetext{
* O agronegócio pode ser compreendido como a soma total das operações de produção e distribuição de suprimentos agrícolas, das operações de produção na unidade de produção, do armazenamento, do processamento e da distribuição dos produtos agrícolas e dos itens produzidos por meio deles (DAVIS; GOLDBERG, 1957).
} 
Altieri acrescenta (1989) que a agricultura familiar tende a optar por se aproximar dos princípios agroecológicos, que acaba por se tornar uma ferramenta mais adequada para o desenvolvimento agrícola de comunidades rurais, pois apresenta-se mais compassivo com a diversidade de modelos da agricultura familiar, onde objetiva gerar mais sustentabilidade, equilíbrio do meio ambiente, segurança alimentar, conservação dos recursos naturais e união para alcançar objetivos comuns.

Camponhola e Valarini (2001) apontam cinco fatores que influenciam essa aproximação dos produtores a produção sustentável, são eles: à percepção de que os grandes cultivos agrícolas tradicionais requerem maior produção das agroindústrias para contrabalançar as quedas de preço influenciadas pelo mercado internacional, que consequentemente aumentam os custos de produção, diminuem os lucros, isto coloca o agricultor familiar em vantagem, por apresentarem menores custos nos processos produtivos; os produtos orgânicos ou agroecológicos ainda se apresentam como um mercado mais seleto, portanto, um nicho, que visa atender os consumidores de um segmento mais restrito, que optam por comprar esses produtos, mesmo sendo mais caros que os convencionais; inclusão dos agricultores familiares nas redes nacionais ou transnacionais de comercialização de produtos orgânicos; produtos especializados, portanto, que não estão no foco das grandes empresas agroindustriais, como alguns tipos de hortaliças e plantas medicinais; e por fim, a diversificação de produtos oferecidos pelos agricultores familiares e a menor dependência de insumos externos, sendo esta, um dos principais entraves no processo produtivo.

Camponhola e Valarini (2001) enfatizam a diversificação da produção, que proporciona ao agricultor familiar, uma rentabilidade estável durante o ano, pois se tem mais produtos a serem oferecidos para repor outros, mesmo se ocorrerem alterações de preços de mercado e imprevistos como mudanças climáticas repentinas e pragas e doenças.

Nesse sentido, a relevância social deste trabalho consiste em mostrar a produtores e interessados, os benefícios sociais, econômicos e ambientais de se produzir de forma sustentável, expondo as dinâmicas referentes aos aspectos que envolvem a produção em si e de funcionamento da unidade de produção familiar.

O presente trabalho objetivou analisar os aspectos econômicos referentes a concessão de insumos, os manejos e o escoamento dos produtos ofertados pela unidade de produção familiar situada no município de Igarapé-Açu, Nordeste Paraense. Também pretendeu-se discutir os desafios e as perspectivas dos agricultores de produzir de forma sustentável, à luz de 
aspectos socioeconômicos e ambientais.

\section{Fundamentação Teórica}

\section{Desenvolvimento sustentável e desenvolvimento rural sustentável}

O conceito de desenvolvimento sustentável surge por meio da Comissão Mundial sobre o Meio Ambiente e Desenvolvimento criada pelas Nações Unidas na década de 80, onde está presente no Relatório Nosso Futuro Comum, também conhecido como Relatório Brundtland, que consistia na proposta de conciliação de desenvolvimento econômico aliado a conservação ambiental (ANDRADE, 2012).

Para Schmitt (1995), o conhecimento acerca de desenvolvimento (rural) sustentável tem como ideia inicial, fundamentalmente o reconhecimento da "insustentabilidade", seja no âmbito social, econômico e ambiental no que tange o desenvolvimento das sociedades atuais.

O desenvolvimento sustentável tem como eixo central a melhoria da qualidade de vida humana dentro dos limites da capacidade de um determinado ecossistema e, na sua consecução, as pessoas, ao mesmo tempo que são beneficiários, são instrumentos do processo, sendo seu envolvimento fundamental para o alcance do sucesso desejado (DE ASSIS, 2006).

Quando o desenvolvimento não se refere ao conjunto de uma sociedade, mas se concentra em áreas, rurais ou urbanas, nas quais se almeja melhorar o nível de vida de sua população, por meio de processos de participação local mediante a valorização de seus próprios recursos, isso se define como desenvolvimento rural ou urbano (GUZMÁN, 2005).

\section{Agroecologia}

Agroecologia, surge como um novo enfoque científico, capaz de dar suporte a uma transição para atividades agrícolas mais sustentáveis e, portanto, contribuir para o estabelecimento de processos de desenvolvimento rural sustentável (CAPORAL; COSTABEBER, 2004).

De uma forma mais direta, Leff (2002) considera que a agroecologia incorpora o funcionamento ecológico necessário para uma agricultura sustentável, mas ao mesmo tempo aplica princípios de equidade na produção, de maneira que suas práticas permitam um acesso igualitário aos meios de vida. Também pode-se considerar que a agroecologia é uma ciência em construção, com características transdisciplinares integrando conhecimentos 
interdisciplinares e incorporando inclusive, o conhecimento tradicional, onde este, se torna um dos elementos centrais da agroecologia (FEIDEN, 2005).

Pode-se considerar que o sistema ideal para a agricultura familiar seria o modelo da agricultura sustentável, onde se fornece uma estrutura metodológica de trabalho para compreensão mais profunda, tanto da natureza dos agroecossistemas, como dos princípios segundo os quais eles funcionam (TUBALDINI et al., 2009).

\section{Transição agroecológica}

Para Costabeber e Moyano (2000), em sua definição semântica, o termo transição pode indicar simplesmente a "ação ou o efeito de passar de um modo de ser ou de estar a outro distinto", ou a "passagem de um estado a outro". Sob esta ótica, a transição pode se referir tanto a fenômenos naturais (efeitos edafoclimáticos, por exemplo) como a fenômenos sociais (processos de mudança social, por exemplo). O processo de transição agroecológica, refere-se a mudança de sistemas e práticas agrícolas tradicionais ou convencionais para a uma agricultura sustentável ou agroecológica (SIQUEIRA, 2010).

Nessa mesma direção, Costabeber (2006, p. 4) afirma que:

"buscar outros rumos para a agricultura e o desenvolvimento rural se
torna, portanto, um imperativo socioambiental da maior relevância no
começo deste novo milênio. A transição agroecológica, referência-
chave das motivações e objetivos de muitos técnicos, estudiosos e
militantes, pode ser definida como um processo gradual, contínuo e
multilinear de mudança nas formas de manejo dos agroecossistemas.
Como propósito mais geral, está a passagem dos atuais padrões de
desenvolvimento rural ou de sistemas de produção de baixa
sustentabilidade para modelos de agricultura e de manejo rural que
privilegiem e incorporem princípios, métodos e tecnologias de base
ecológica. Isso implica não somente a busca de maior racionalização
produtiva com base nas especificidades biofísicas de cada
agroecossistema, mas também uma mudança nas atitudes e valores dos
atores sociais em relação ao manejo e conservação dos recursos."

Gliessman (2005) acrescenta que o processo de transição agroecológica se constitui em 3 etapas ou níveis: A primeiro refere-se à diminuição gradual do uso de insumos externos, caros, insuficientes e ambientalmente degradantes, com intuito de maximizar a eficiência das práticas convencionais. A segunda etapa constitui na substituição desses insumos externos maléficos ao meio ambiente, por insumos orgânicos e práticas alternativas. E por fim a terceira etapa, a 
reelaboração dos sistemas de produção, para que possam trabalhar baseados em um novo arranjo de processos ecológicos.

\section{Metodologia}

O tipo da pesquisa caracteriza-se como estudo de caso e de natureza qualitativa quantitativa. O estudo foi realizado no Sítio Agroecológico Tolú, situado no município de Igarapé-Açu, Nordeste Paraense. A unidade de produção familiar estudada é composta por três integrantes, são eles: a Senhora L. S., o Senhor T. L., os dois formando um casal e a Senhora J. S. sendo a mãe da Senhora L. S. O sítio fica situado às margens da rodovia PA 320, km 2, as coordenadas são $-01^{\circ} 08^{\prime} 05,04^{\prime \prime}$ Norte e $-47^{\circ} 39^{\prime} 14,05^{\prime}$ ' Oeste (Figura 1). O clima da localidade segundo a classificação de Köppen é caracterizado por regimes de pluviométricos bastante acentuados (ANDRADE et al., 2017).

Figura 1 - Mapa de localização do Sitio Agroecológico Tolú, Nordeste paraense.

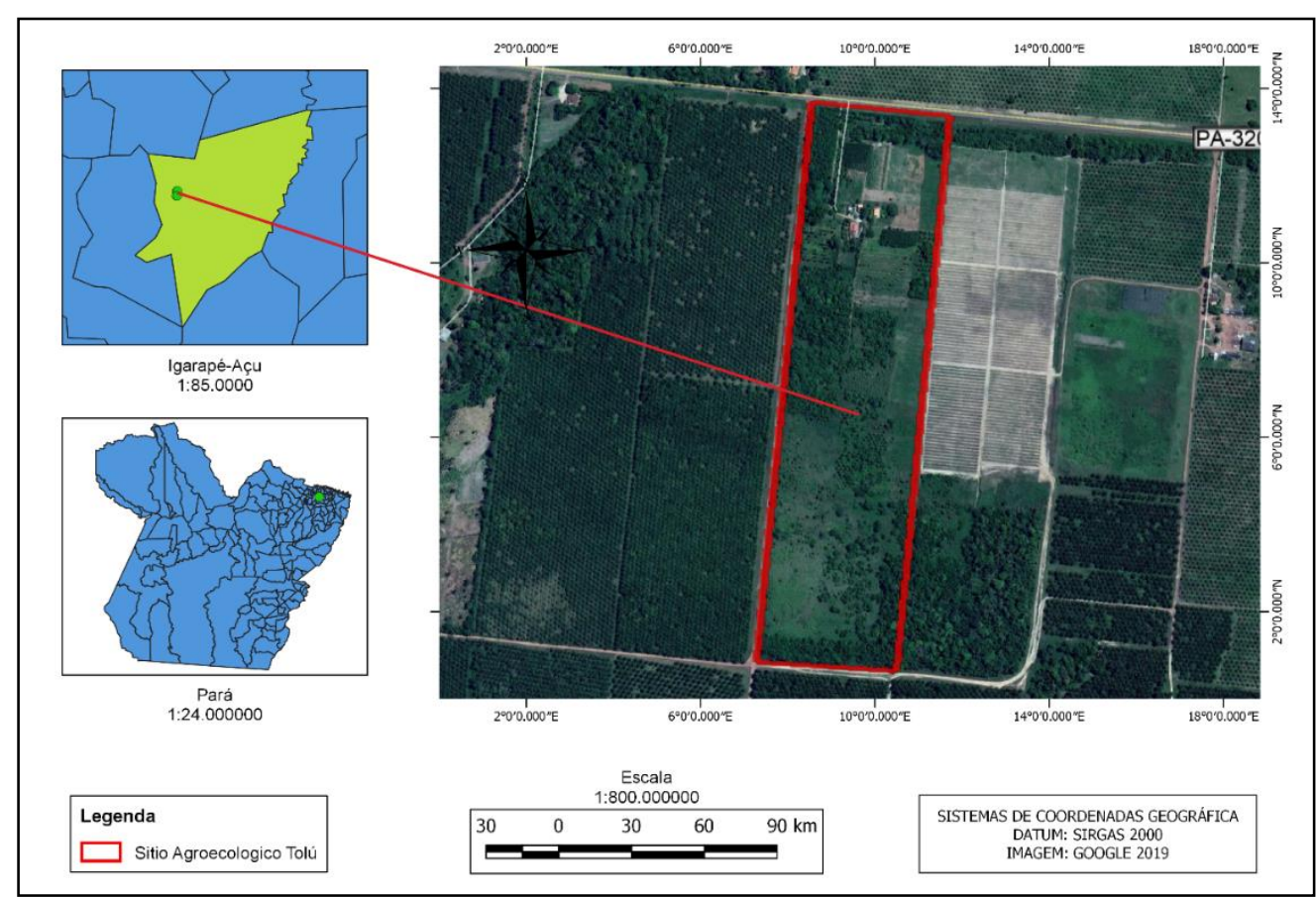

Fonte: Própria (2019)

A pesquisa foi realizada por meio de entrevista e aplicação de um questionário semiestruturado contendo 15 perguntas abertas e fechadas no dia 07 de fevereiro de 2019 . Foram coletadas informações sobre as características socioeconômicas (escolaridade, número de pessoas na família, tempo de atuação na agricultura e participação em curso de capacitação 
agrícola) e os aspectos de produção da unidade familiar, relacionados aos segmentos antes da porteira (aquisição de insumos), dentro da porteira (manejos, produtos, beneficiamento, agregação de valor, destinação de resíduos da produção) e após a porteira (marketing, comercialização dos produtos) (ARAÚJO, 2007).

\section{Resultados e Discussão}

\section{Caracterização socioeconômica dos membros da família do sítio agroecológico Tolú}

Segundo dados fornecidos pelos agricultores familiares, a idade da Senhora L. S., o Senhor T. L. e a Senhora J. S é 38, 53 e 65 anos, respectivamente. Os dois primeiros são os membros da família que atuam, diretamente, no desenvolvimento produtivo da unidade de Produção Agrízcola (UPA), onde participam desde a captação de insumos necessários a produção até a comercialização dos produtos orgânicos, com tempo de trabalho de sete anos na agricultura. Já o terceiro membro da família não participa diretamente, mas não se distância do processo produtivo, onde auxilia na alimentação e nos serviços gerais da casa (Tabela 1).

Tabela 1: Dados socioeconômicos dos integrantes da Unidade Familiar.

\begin{tabular}{cccccc}
\cline { 2 - 6 } & IDADE & $\begin{array}{c}\text { ATUAÇÃO } \\
\text { DIRETA NO } \\
\text { PROCESSO } \\
\text { PRODUTIVO }\end{array}$ & $\begin{array}{c}\text { TEMPO DE } \\
\text { TRABALHO NA } \\
\text { AGRICULTURA }\end{array}$ & $\begin{array}{c}\text { NÍVEL DE } \\
\text { ESCOLARIDADE }\end{array}$ & $\begin{array}{c}\text { CURSOS DE } \\
\text { CAPACITAÇÃO }\end{array}$ \\
\hline $\begin{array}{c}\text { SENHORA } \\
\text { L. S. }\end{array}$ & 38 & $\operatorname{sim}$ & 7 anos & Graduação & $\begin{array}{c}\text { Engenharia } \\
\text { Agronômica e } \\
\text { manejo de SAF's }\end{array}$ \\
\hline $\begin{array}{c}\text { SENHOR } \\
\text { T. L. }\end{array}$ & 53 & $\operatorname{sim}$ & 7 anos & Técnico & $\begin{array}{c}\text { Agropecuário e } \\
\text { manejo de SAF's }\end{array}$ \\
\hline $\begin{array}{c}\text { SENHORA } \\
\text { J.S. }\end{array}$ & 65 & Não atua & Não atua & $\begin{array}{c}\text { Ensino médio } \\
\text { completo }\end{array}$ & Não possui \\
\hline
\end{tabular}

Fonte: Própria (2019)

No que se refere ao grau de escolaridade constatou-se que a Senhora J. S. possui $\theta$ ensino médio completo, a Senhora L. S. possui formação em Engenharia agronômica e o Senhor T. L. possui nível técnico em Agropecuária, e ambos cursaram no Instituto Federal do Pará (IFPA). Ademais, casal proprietário do sítio também possui formação em manejo de Sistemas Agroflorestais, conforme é mostrado na Tabela 1.

\section{Atividade antes da produção}

\section{Concessão de insumos}

De acordo com os agricultores do sítio agroecológico Tolú a aquisição de insumos necessários a produção agrícola é feita por meio da deposição de resíduos advindos das 
agroindústrias locais, onde caminhões das mesmas se direcionam a propriedade para despejar cascas de ovos, penas dos abatedouros de frango (Fotografias 1 e 2), cinzas de padaria e sementes de diversos tipos de frutas de despolpadoras (Fotografia 3 e 4 ).

Fotografias 1 e 2: Cascas de ovos de criadores e penas dos abatedouros de frango do município de Igarapé-Açú, PA.

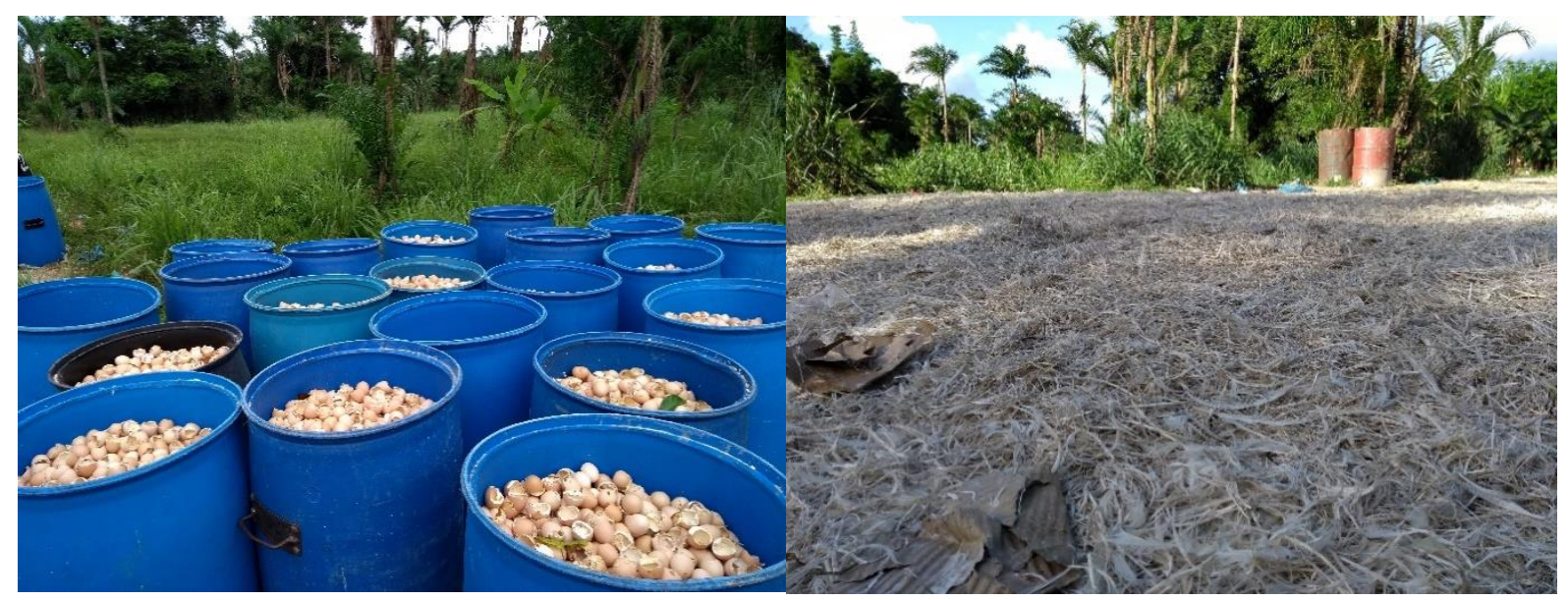

Fonte: Própria (2019).

A concessão destes insumos foi feita por meio de acordo com as agroindústrias, onde os agricultores, utilizando-se da Lei $\mathrm{n}^{\mathrm{o}}$ 12.305/2010, que estabelece a total responsabilidade das empresas referentes à destinação adequada dos resíduos orgânicos gerados pelas mesmas. De acordo com os agricultores o descarte desses materiais não estava sendo realizado da maneira adequada. Pois, muitas vezes, eram depositados em margens de rios, lagos e outros locais a céu aberto. Sendo assim, foi acordado que o Sitio Agroecológico Tolú se tornaria uma unidade receptora e recicladora de resíduos orgânicos produzidos por essas unidades de produção e processamento.

Fotografias 3 e 4: Cinzas de padaria e sementes de despolpadoras locais do município de Igarapé-Açú, PA.

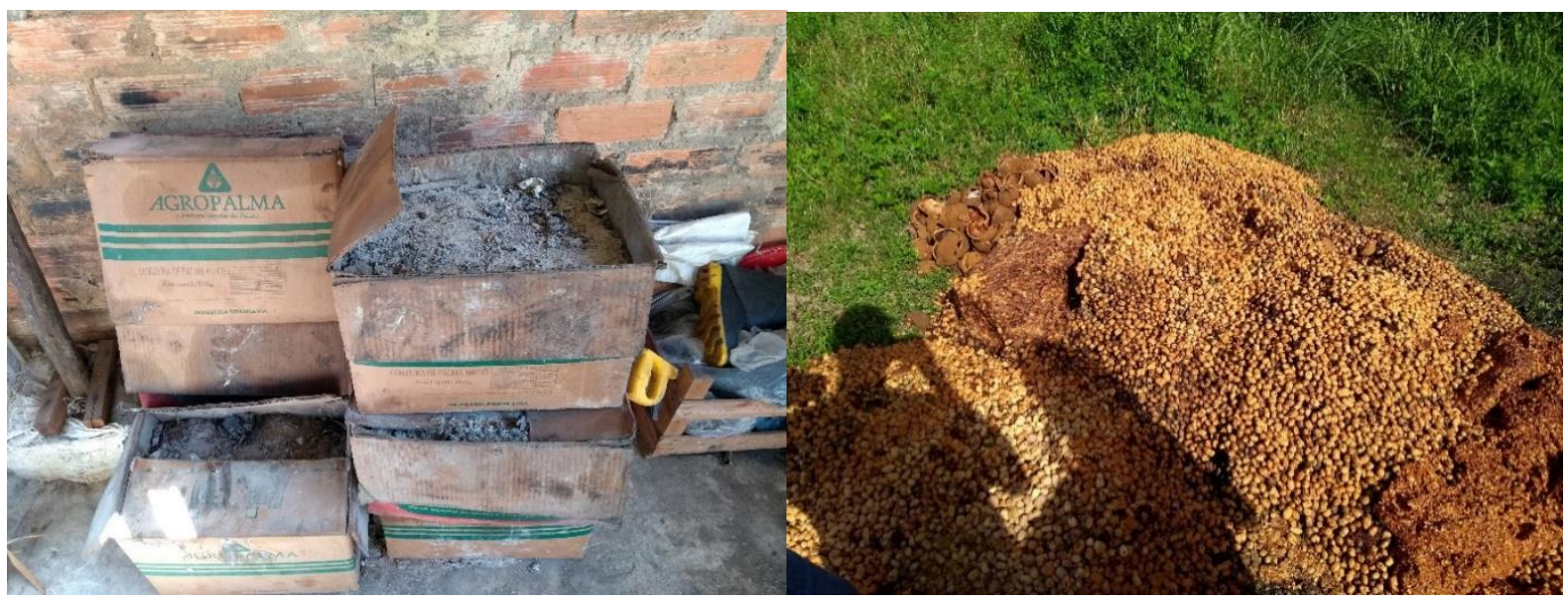


Fonte: Própria (2019).

Contudo, ainda se tem muitos problemas com resíduos inorgânicos como plásticos e metais que acompanham os resíduos orgânicos. Sendo assim, os agricultores contratam dois trabalhadores para fazer essa separação e assim facilitar a utilização desses materiais orgânicos na adubação laminar* do solo da propriedade em questão. Atualmente, os insumos advindos desses estabelecimentos comerciais são a base para adubações das culturas produzidas pela unidade familiar, como horta e em seus sistemas agroflorestais (SAF's) (Fotografias 5 e 6).

Fotografias 5 e 6: Utilização dos resíduos orgânicos na adubação laminar do solo da unidade familiar, Nordeste

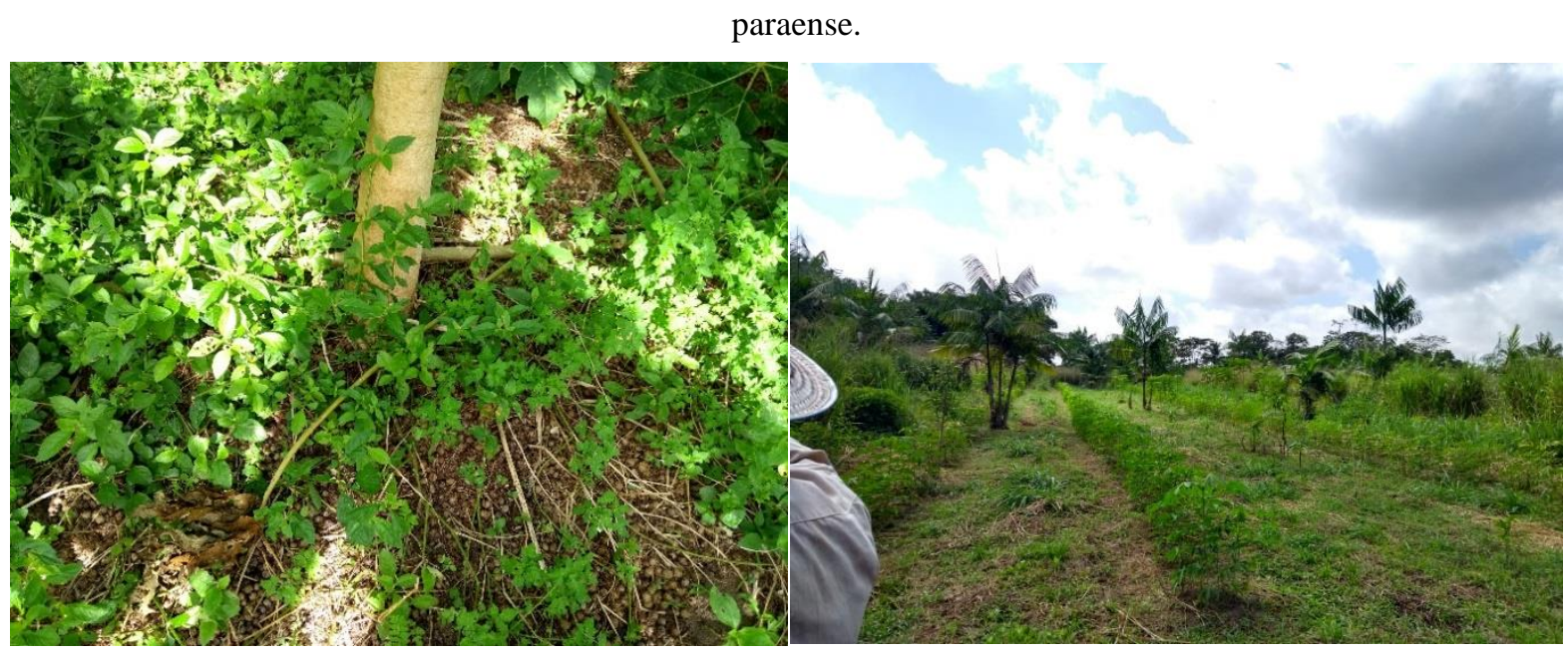

Fonte: Própria (2019).

Os fertilizantes são desenvolvidos dentro da propriedade, onde é realizado a mistura de diversos componentes orgânicos (Fotografia 7), também aproveitando-se dos húmus de Embuá (Lulus sabulosuscylindroiulus) como forma de complementar a adubação.

Fotografia 7: Tanques de armazenamento de fertilizantes orgânicos.

\footnotetext{
* Adubação que consiste em depositar o material diretamente sobre o solo, ocasionando processos fermentativos aeróbios e proporcionando um ambiente favorável, resultando no aumento da fauna edáfica que auxilia na decomposição dos componentes orgânicos
} 


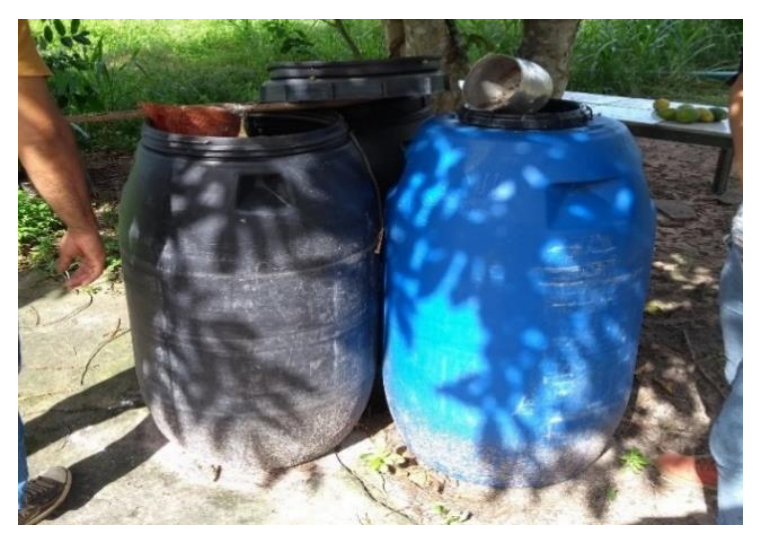

Fonte: Própria (2019).

Segundo os agricultores, os fatores que motivaram a utilização da espécie foi sua existência em abundância na unidade familiar e a sua maior eficiência na reciclagem de nutrientes quando comparadas as minhocas. Antunes et al. (2018) reforçam que esse tipo de composto orgânico demonstra o potencial de produção de excelente qualidade no desenvolvimento de plantas.

\section{Atividades de produção}

A técnica mais utilizada pelos agricultores nos cultivos é a adubação laminar (Fotografias 8, 9, 10, 11 e 12), que tenta assemelhar-se a formação de serapilheira que ocorre em florestas. Nunes e Santos (2009 apud ARAÚJO, 2017) afirmam que:

O método de compostagem laminar pode ser muito benéfico e uma alternativa vantajosa para o produtor rural, visto que, carece de baixo emprego de mão-de-obra, tornando ainda possível a redução parcial ou total de fertilizantes sintéticos. Ressaltam, ainda, que o processo é menos árduo e demorado quando comparado ao da compostagem tradicional.

Fotografias 8 e 9: Técnica da compostagem laminar utilizada no sítio agroecológico Tolú, Nordeste paraense. 


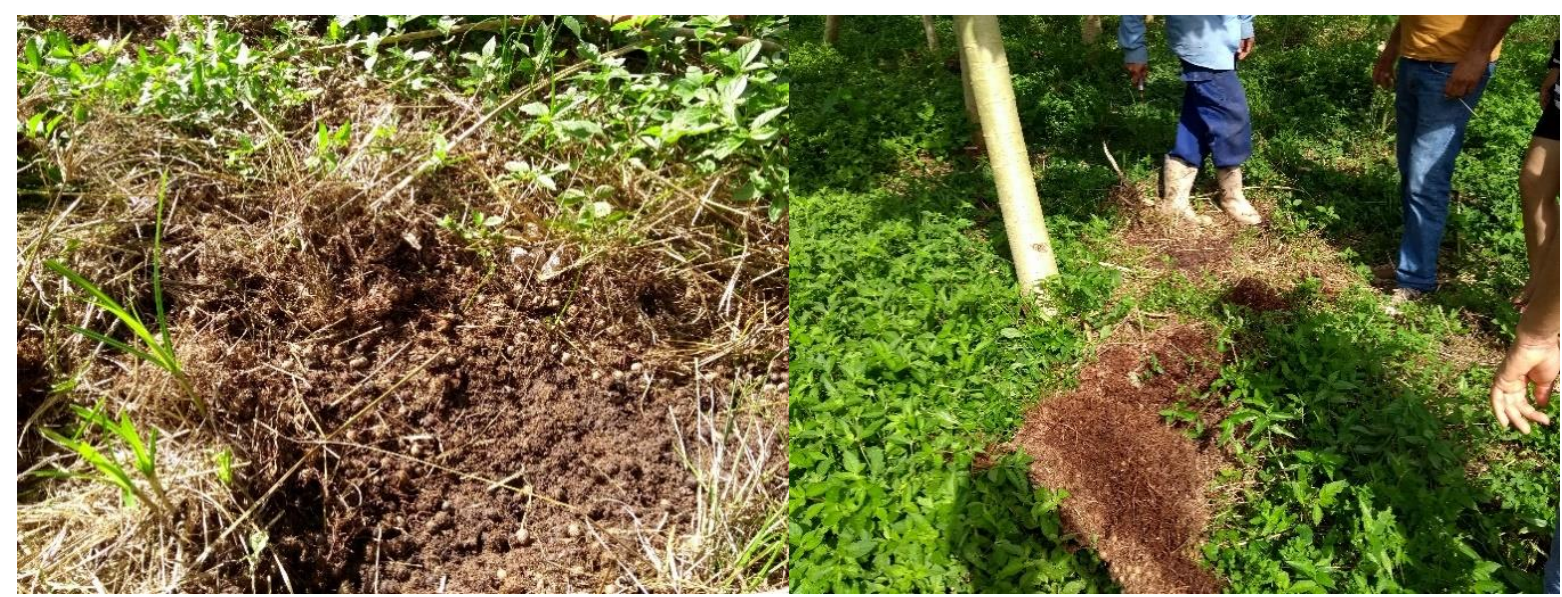

Fonte: Própria (2019)

$\mathrm{Na}$ propriedade a técnica de adubação laminar tem sido empregada para aumentar a produtividade de cultivos de hortaliças, frutas e espécies florestais. De acordo com Schwengber et al. (2007) a compostagem laminar pode ser utilizada na recuperação da fertilidade do solo, sendo caracterizada pela produção de composto orgânico no local de cultivo de hortaliças e fruteiras, o que contribui para diminuição de custos com o fator mão-de-obra, bom emprego de chorume produzido e controle de plantas daninhas nas unidades de produção agrícola. Logo, notou-se que esta técnica de adubação é mais apropriada para área em estudo, pois trata-se de uma propriedade que possui histórico de solo degradado pela atividade de pecuária extensiva.

Fotografias 10, 11 e 12: Técnica da compostagem laminar no cultivo de hortaliças.

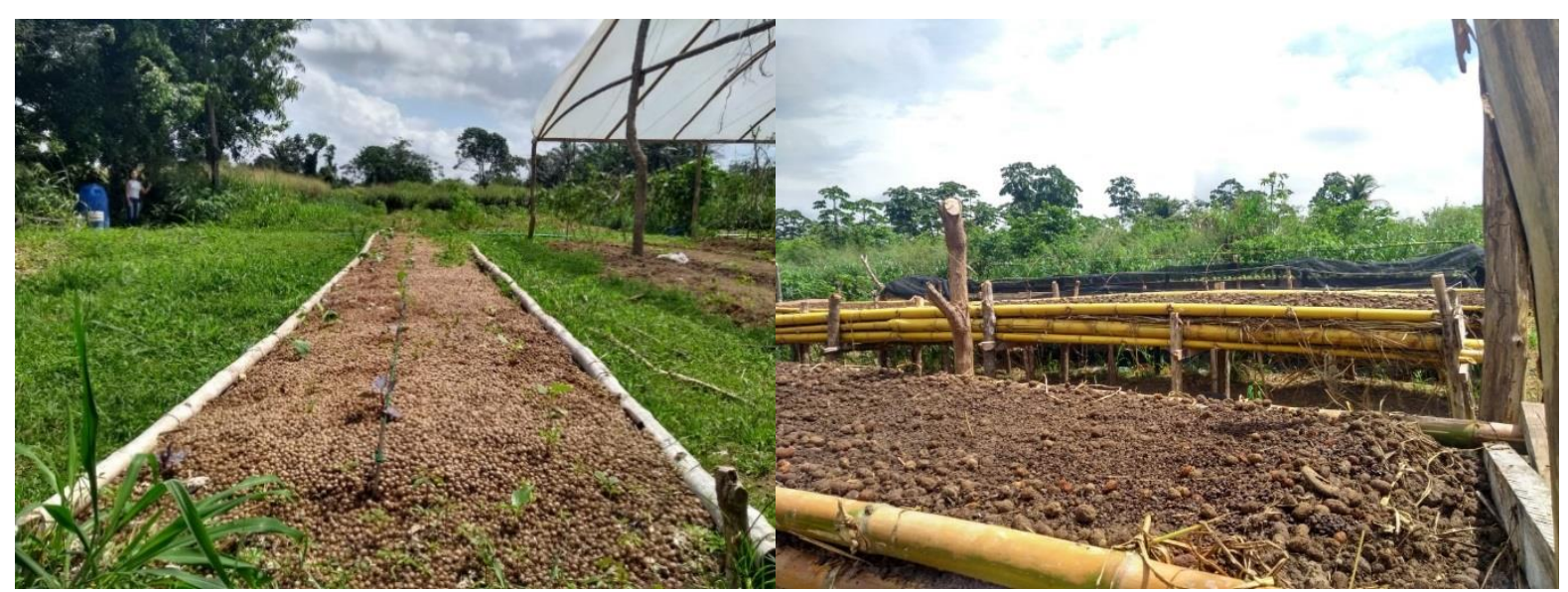

Fonte: Própria (2019).

Outras técnicas empregadas são a roçagem utilizando roçadeira em de áreas dominadas por capim elefante (Pennisetumpurpureum) e outras espécies que se encontram na área (Fotografia 13), e o controle de pragas valendo-se de armadilhas em volta da área de cultivo (fotografia 14). 
Fotografias 13 e 14: Técnica roçagem e controle de pragas. Fonte: Acervo dos autores (2018).

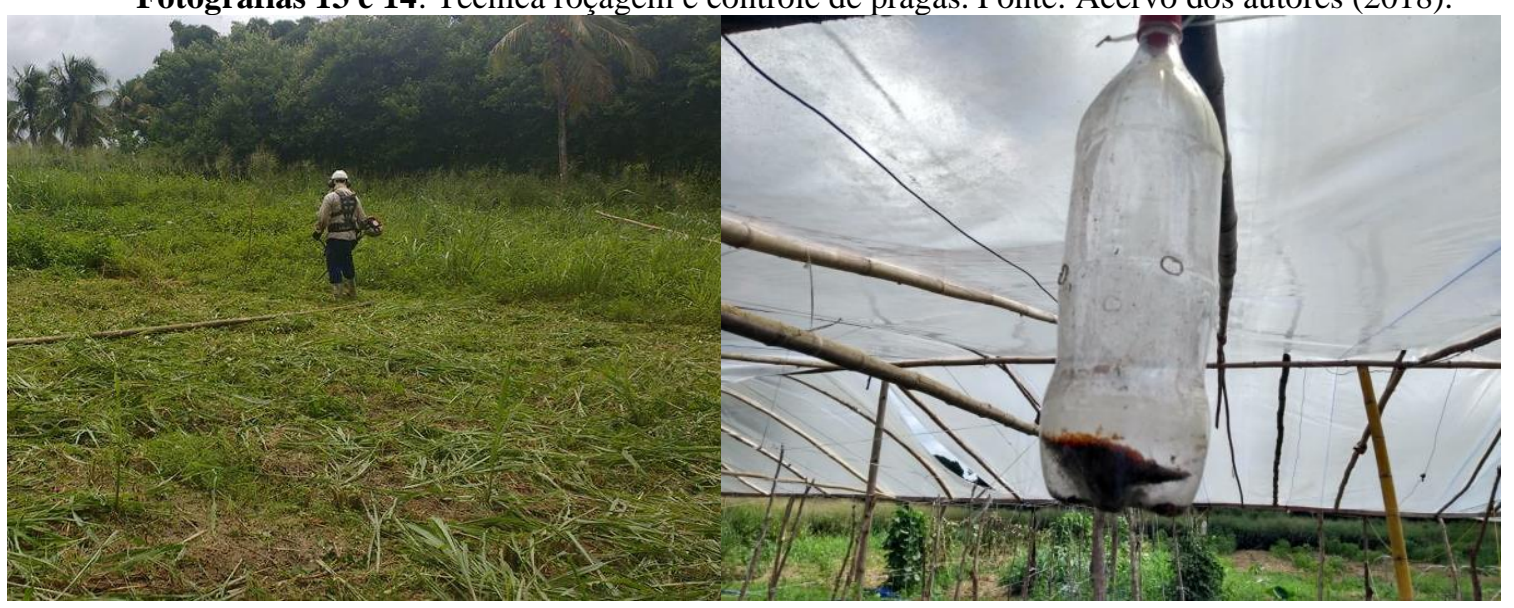

Fonte: Própria (2019).

\section{Produtos ofertados pelo sítio agroecológico Tolú}

A produção do Sitio Agroecológico Tolú apresenta grande diversidade (Tabela 2), onde foi possível observar a oferta desde culturas bastante comercializadas por agricultores familiares, como, coentro, jambu, abóbora e coco (Fotografia 14), até culturas mais difíceis de serem encontradas, como o Ora-pro-nóbis (Pereskiaaculeata) (Fotografia 15).

Tabela 2: Produtos ofertados pela unidade familiar agrícola.

\begin{tabular}{ccccc}
\hline HORTALIÇAS & FRUTÍFERAS & $\begin{array}{c}\text { ORIGEM } \\
\text { ANIMAL }\end{array}$ & MEDICINAIS & OUTROS \\
\hline Alface & Limão & Frangos & Mastruz & Adubo orgânico \\
\hline Couve & Coco verde & Ovos & Manjericão & Biomassa de banana verde \\
\hline Macaxeira & Coco seco & Mel & Erva Cidreira & Tucupi \\
\hline Mandioca & Laranja & & Capim Santo & Farinha gourmet \\
\hline Coentro & Acerola & Mastruz & Macaxeira ralada \\
\hline Abóbora & Mamão & Aranto & Macaxeira descascada \\
\hline Jambu & Banana & Óleo de & Macaxeira com casca \\
\hline Almeirão & & Andiroba & Biscoitos caseiros \\
\hline Taioba & & & \\
\hline Tomate cereja & & & \\
\hline Mostarda & & & \\
\hline Ora-pro-nóbis & & \\
\hline Berinjela & & & \\
\hline
\end{tabular}

Fonte: Própria (2019) 
Fotografia 16- Ora-pro-nóbis (Pereskiaaculeata) cultivado na propriedade familiar.

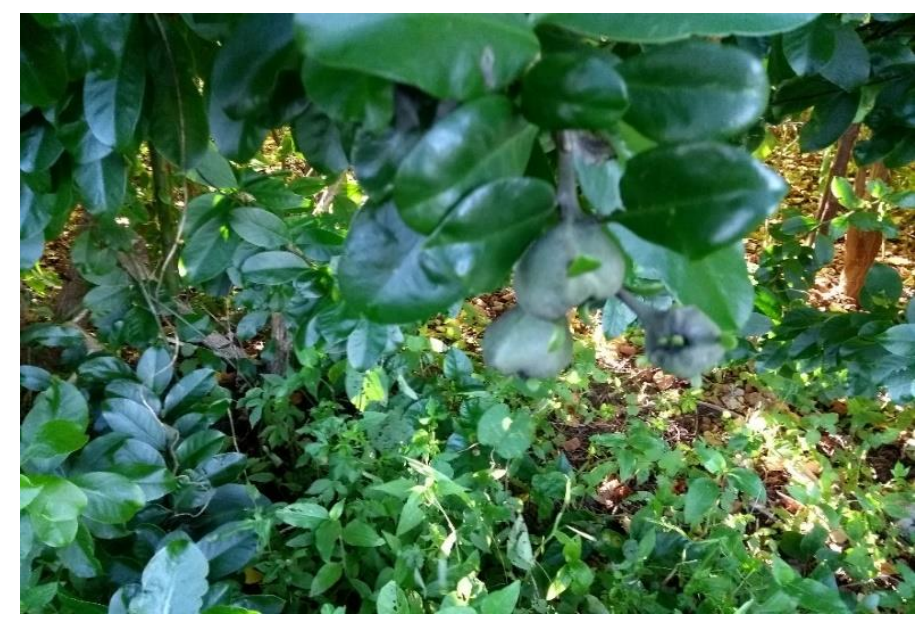

Fonte: Própria (2019).

Também são produzidos produtos de origem animal, como frangos, ovos, mel e produtos classificados como medicinais, a exemplo do manjericão, erva cidreira, capim santo, mastruz e Aranto. Ainda é oferecido pela unidade, adubo orgânico, óleo de andiroba, biomassa de banana verde, almeirão, mostarda, taioba, limão, tomate cereja, tucupi e farinha gourmet (Fotografia 17). Onde o excedente da produção permanece na propriedade para propiciar a segurança alimentar dos produtores.

Fotografia 17: Alguns produtos ofertados pela unidade familiar agrícola.

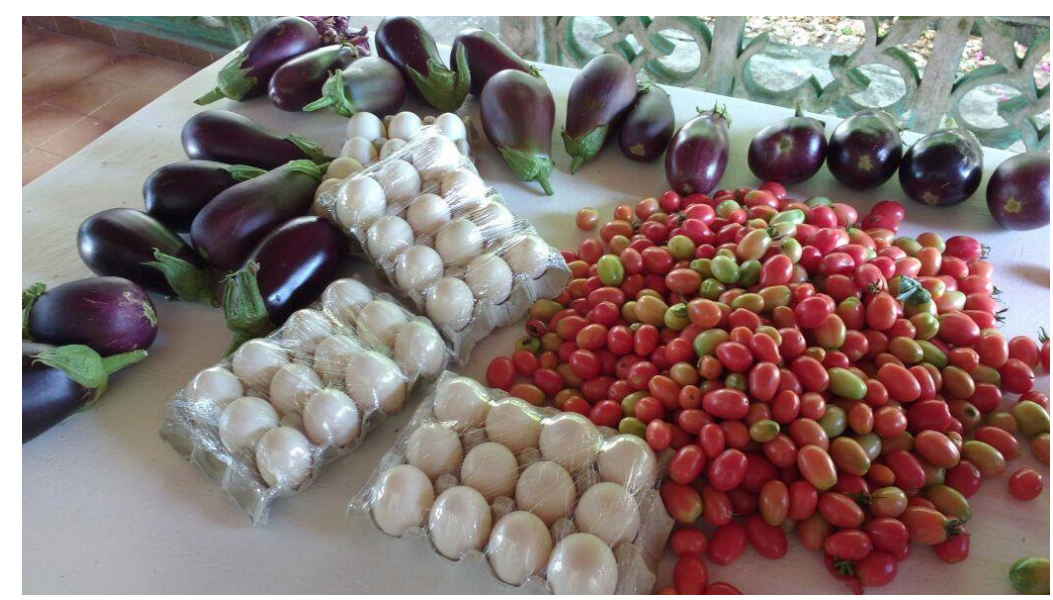

Fonte: Própria (2019).

\section{Beneficiamento, agregação de valor e Comercialização}

Segundo os agricultores, os produtos beneficiados são a banana que é processada para se tornar biomassa, a macaxeira que é ralada e descascada, também é realizada o envaze da água de coco, andiroba e mel em recipientes. Ademais algumas frutas são processadas para se 
obter geleias; utilizam-se da fécula de mandioca para confeccionar biscoitos; e também são confeccionadas embalagens para realizar a comercialização de hortaliças. A realização desses processos se torna vantajosa por agregar valor aos produtos (Fotografia 18), conforme expõem Oliveira et al., (2011), onde a matéria-prima, em vez de ser vendida por preços reduzidos e declinantes, passa a ser processada, o que agrega valor aos preços recebidos.

Fotografia 18: Produtos beneficiados pelos agricultores.

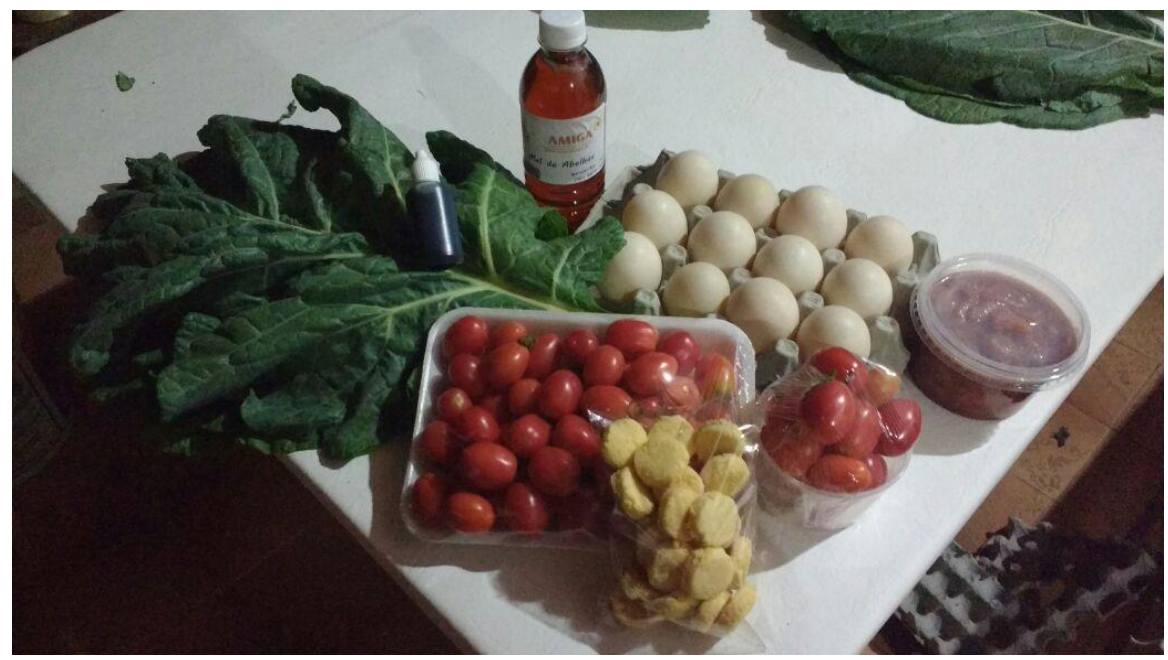

Fonte: Própria (2019)

A comercialização é realizada por meio da entrega a domicílio, onde os agricultores deslocam-se até os municípios de Belém do Pará, Castanhal e Capanema. Segundo os agricultores, anteriormente vendiam seus produtos no Centro de Abastecimento do Pará CEASA, onde não ocorria diferenciação de preço dos produtos da agricultura convencional dos orgânicos.

A partir do direcionamento das vendas para consumidores que atribuem maior valor aos produtos orgânicos, observou-se uma variação da receita de $\mathrm{R} \$ 3.000,00$ para $\mathrm{R} \$ 6.000,00$ da unidade de produção familiar. Esse aumento de receita deve-se, em parte, a utilização de redes sociais para divulgação da variedade de produtos produzidos pela unidade familiar e seus benefícios trazidos a saúde após o consumo. Logo, o marketing é feito por meio digital, promovendo a disseminação de informações quanto aos produtos ofertados e a proximidade dos clientes com os agricultores familiares, eliminando a figura do atravessador.

A utilização das redes sociais proporciona, ainda, aos clientes a facilidade de formarem cestas personalizadas, ou seja, cada cliente monta seus pedidos e enviam por meio de mensagem para os agricultores (Fotografia 19).

Fotografia 19: Marketing digital do Sitio agroecológico Tolú. 


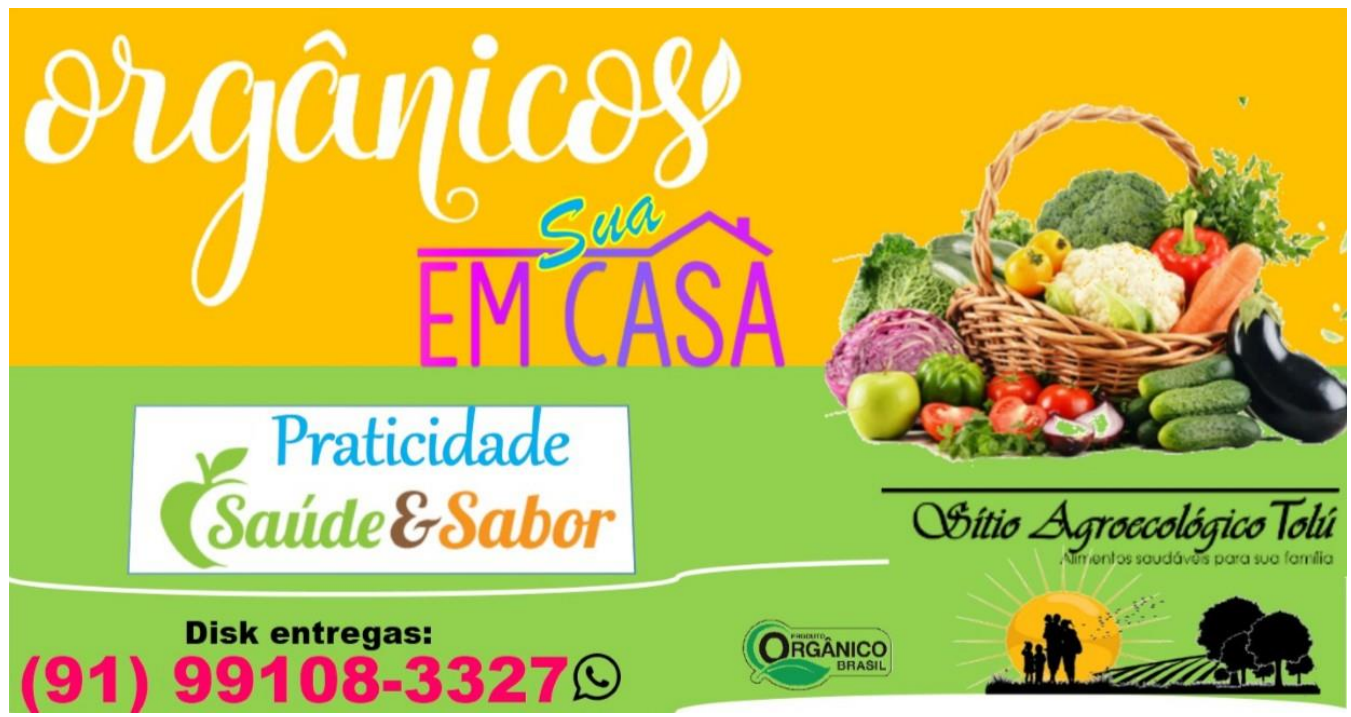

Fonte: Própria (2019)

\section{Conclusões}

Pode-se concluir que o fato de produzir de forma sustentável trouxe muitos benefícios econômicos, ambientais e sociais para consumidores e produtores. A unidade familiar demonstrou que através da produção orgânica é possível obter grande diversificação de produtos, agregação de valor e aumento de receita.

\section{Referências}

ALTIERI, Miguel. Agroecologia: As bases científicas da agricultura alternativa. Trad. Patrícia Vaz. PTA/FASE. Rio de Janeiro. p. 240, 1989.

ANDRADE, H. (2012). Desenvolvimento, Rural Sustentável " uma visão territorial ". Caderno de formação da Organização das Nações Unidas para Agricultura e Alimentação - FAO, n. 1, p. 68.

ANDRADE, V. M. S. de; CORDEIRO, I. M. C. C.; SCHWARTZ, G.; RANGELVASCONCELOS, L. G. T.; OLIVEIRA, F. de A. Considerações sobre clima e Aspectos edafoclimáticos da Mesorregião nordeste paraense. In: CORDEIRO, I. M. C. C.; RANGELVASCONCELOS, L. G. T.; SCHWARTZ, G.; OLIVEIRA, F. de A. (Orgs.). Nordeste Paraense: panorama geral e uso sustentável das florestas secundárias. 1.ed. Belém: EdUFRA, cap.2, p.59-96, 2017

ARAÚJO, Francisca Luciana Santos et al. Compostagem laminar: uma alternativa sustentável para produção na agricultura familiar, Igarapé-Açu, PA. In $10^{\circ}$ SEMINARIO INTERNACIONAL DE DESENVOLVIEMENTO RURAL SUSTENTÁVEL, COOPERATIVISMO E ECONOMIA SOLIDÁRIA E FEIRA DE CIÊNCIA, TECNOLOGIA E INOVAÇÃO SOCIAL, 23 a 25, 2017, Castanhal: IFPA, p. 3, 2017. 
ARAÚJO, M. J. Fundamentos de agronegócios. Atlas, São Paulo, 2003.

CAMPANHOLA, C.; VALARINI, P. J. A agricultura orgânica e seu potencial para o pequeno agricultor. Cadernos de Ciência \& Tecnologia, Brasília, v. 18, n. 3, p. 69-101, dez. 2001. Disponível em: <http://seer.sct.embrapa.br/index.php/cct/article/view/8851/4981>. Acesso em: 21 fev. 2019.

CAPORAL, F. R.; COSTABEBER, J. A. Agroecologia e extensão rural: contribuições para a promoção do desenvolvimento rural sustentável. Brasília: MDA/SAF/DATER-IICA, 2004.

COSTABEBER, J. A. Transição agroecológica: rumo à sustentabilidade. Agriculturas: Experiências em Agroecologia, AS-PTA, v. 3, n. 3, Rio de Janeiro, p. 4-5, 2006.

COSTABEBER, José Antônio; MOYANO, Eduardo. Transição agroecológica e ação social coletiva. Agroecologia e Desenvolvimento Rural Sustentável, v. 1, n. 4, p. 50-60, 2000.

DE ASSIS, Renato Linhares. Desenvolvimento rural sustentável no Brasil: perspectivas a partir da integração de ações públicas e privadas com base na agroecologia. Economia Aplicada, v. 10, n. 1, p. 75-89, 2006.

DE SOUSA ANTUNES, Luiz Fernando et al. Desempenho agronômico da alface crespa a partir de mudas produzidas com gongocomposto. Revista Brasileira de Agropecuária Sustentável, Viçosa, MG, v. 8, n. 3, dez. 2018. Disponível em: <https://periodicos.ufv.br/ojs/rbas/article/view/3009>. Acesso em: 21 fev. 2019.

FEIDEN. A. Agroecologia: introdução e conceitos. In: AQUINO, A.M.; ASSIS R.L. (Ed.) Agroecologia: princípios e técnicas para uma agricultura orgânica sustentável. Brasília, DF: Embrapa Informação Tecnológica, p. 51-68, 2005.

GLIESSMAN, S. R. Agroecologia: processos ecológicos em agricultura sustentável. 3.ed. Porto Alegre: UFRGS, 2005.

GUZMÁN, E. S. Agroecologia e desenvolvimento rural sustentável. In: AQUINO, A.M.; ASSIS R.L. (Ed.) Agroecologia: princípios e técnicas para uma agricultura orgânica sustentável. Brasília, DF: Embrapa Informação Tecnológica, 2005. Cap. 4, p. 103-132.

LAGO, A.; LENGLER, L.; CORONEL, D. A.; SILVA, T. N. Agricultura familiar de produtos orgânicos: um olhar sob a ótica do marketing. Revista de Extensão Rural, v. 13, p. 96-119, 2006.

NUNES, M. U. C.; SANTOS, J. R dos. Alternativas tecnológicas para o aproveitamento de resíduos de coqueiro gigante para produção de adubo orgânico, compostagem e outras. Embrapa Tabuleiros Costeiros, Capítulo em livro técnico-científico (ALICE), 2009.

OLIVEIRA, D.; GAZOLLA, M.; SCHNEIDER S. Produzindo novidades na agricultura familiar: agregação de valor e agroecologia para o desenvolvimento rural. Cadernos de Ciência \& Tecnologia, Brasília, v. 28, n. 1, p. 17-49, jan./abr. 2011. 
SIQUEIRA, Haloysio Miguel de et al. Transição agroecológica e sustentabilidade dos agricultores familiares do Território do Caparaó-ES. Revista Brasileira de Agroecologia, v. 5 , n. 2, p. 247-263, 2010.

SCHMITT, Claudia J. Sociedade, natureza e desenvolvimento sustentável: uma abordagem preliminar. Porto Alegre: PPGS/UFRGS, 1995.

SCHWENGBER, J. E.; SCHIEDECK, G.; MEDEIROS GONÇALVES, M. Compostagem laminar uma alternativa para o manejo de resíduos orgânicos. 2008. 4p. (Comunicado técnico, 169).

VEIGA, J. E. Agricultura familiar e sustentabilidade. Cadernos de Ciência \& Tecnologia, Brasília, v.13, n. 3, p. 383-404, 1996.

WANDERLEY, M. N. B. A valorização da agricultura familiar e a reivindicação da ruralidade no Brasil. UFPR, Pernambuco, n. 2, p. 30-33, 2000. 